A - preparing concepts

$\mathrm{B}$ - formulating methods

$\mathrm{C}$ - conducting research

$\mathrm{D}$ - processing results

E - interpretation and conclusions

$\mathrm{F}$ - editing the final version

\section{Functional state and the occurrence of injuries among young athletes practicing cross-country skiing}

\author{
Karolina Koczta ${ }^{1, A-E}$ (D), Aleksandra Truszczyńska-Baszak ${ }^{1, A-B, D-F}$ (D), \\ Natalia Twarowska ${ }^{2, F, *}$ (D)
}

${ }^{1}$ Faculty of Rehabilitation, Józef Piłsudski University of Physical Education, Warsaw, Poland

${ }^{2}$ Doctor Studies, Faculty of Physical Education, Józef Piłsudski University of Physical Education, Warsaw, Poland

*Correspondence: Natalia Twarowska; Józef Piłsudski University of Physical Education, Marymoncka 34, 00-968 Warsaw, Poland;

e-mail: natalia.twarowska@gmail.com

\title{
Abstract
}

Introduction: Despite the positive aspects of taking up physical activity, sport, in general, is inseparably associated with injuries, as well as straining or overloading of the musculoskeletal system. The aim of this study was to determine the functional state and injuries among young athletes practicing cross-country skiing.

Material and methods: A total of 65 individuals participated in the study. The test group consisted of 33 individuals practicing cross-country skiing, while the control group consisted of 32 persons not involved in this sport. The study was divided into two stages. The first stage consisted of a survey in which participants completed a personal questionnaire and were asked to answer 17 questions. Next, the Funtional Movement Screen (FMS) test was carried out in both groups using a specialty devised assessment form.

Results: The assessment of the risk of injury in both groups was similar, no statistically significant differences were found in this respect $(p=0.992)$. No statistically relevant relation was between the number of injuries sustained and the training experience of individuals in the test group $(\mathrm{p}=0.056)$. There was no statistically significant relationship between the number of sustained injuries and the training experience of individuals included in the test group $(p=0.056)$, although this relationship was close to the threshold of statistical significance.

Conclusions: Cross-country skiing training had no significant effect on musculoskeletal injuries. The FMS test result did not correlate with previously sustained injuries. Individuals who adopted preventive training schemes were less likely to sustain injuries.

\section{Keywords: FMS test, injury, cross-country skiing}

\section{Introduction}

The introduction of physical activity at an early age is extremely important, as it conditions children's proper physical development and growth. Promoting active and healthy lifestyle strengthens proper health habits, prevents lifestyle diseases, has a positive effect on the psyche and overall mental health $[1,2]$. Despite positive aspects of taking up physical activity, sport, in general, is inseparably associated with injuries, as well as straining or overloading of the musculoskeletal system.

Training programs are developed based on movement patterns, i.e. sequential movements which stem 
from the biomechanics of movement. Incorrectly repeated movement patterns during the training of given sport lead to a decrease in our motor potential and increase the risk of injury [3].

Sport is subject to professionalization and commercialization, unfortunately, this often leads athletes to push the boundaries and limits of the human body. To meet the requirements of their club and sponsors, athletes often neglect certain phases of the training cycle. Reasons may vary and may include shorter resting periods, lack of awareness, or stress stemming, among other factors, from competition [4].

Periodicity, i.e. adhering to appropriate training routines in the training cycle which are included in the training plan is extremely important. A comprehensive assessment of a given athlete or athletes should be done before the preparatory period to reduce the risk of injury during the season. The basic error many coaches make is they monitor fitness conditioning and skills of a given athlete, while the assessment of the condition and cooperation between the muscular and nervous system is ignored. This results in an incomplete preparation of a given athlete for the season and increases the odds of overloads and possible injuries [5].

Cross-country skiing is regarded as one of the sport disciplines with moderate risk trauma and injuries [6]. Although not a contact sport, skiers at the professional level may reach speeds of up to 80 kilometers per hour, so any fall may present a serious threat. Research shows that the most common injuries are bruising and wounds resulting from falling while performing skating style. The joint that is the most at risk for injuries is the knee joint [7].

In cross-country skiing, two main techniques can be distinguished. The first is the classic style, which is similar to the natural movement of walking or running. The classic style is characterized by the parallel movement of skis and alternate work of the upper limbs, in which the alternating movement consisting of the variable work of the upper limbs with the lower limbs can be distinguished. The movement of the lower limbs occurs in three phases: kick, swing and glide [8]. The second technique is the skating style. It is characterized by the angular position of the skis to the skiing direction. In this style, four steps can be distinguished [9].

Speed is the main difference between classic and skating style in cross-country skiing. In skating style, the skiers reach speeds $15-20 \%$ greater than in the classic style, skis are shorter and poles are longer. Skating style requires better preparation on the part of a given athlete [8].

In the available literature, few publications were found regarding the functional assessment of young cross-country skiers and the selection of the appropriate form of training individually tailored for a given athlete [7]. The correct functional assessment of athletes and the implementation of optimal training methods is particularly important when practicing sports at a young age. This can be reflected in the better performance of a given athlete later on. That is why it is so important to broaden the subject of injury concerning athletes practicing cross-country skiing in current literature. High level of physical fitness athletes plays an important role in preventing injuries and overloads. One of the methods of assessment of the functional state athletes which may aid in the prevention of injuries is the FMS - Functional Movement Screen test [10].

The aim of this study was to determine the functional state and injuries among young athletes practicing cross-country skiing.

\section{Material and methods}

Upon obtaining the consent of the Senate Research Ethics Committee No. SKE 01-16/2018, 65 individuals (39 girls and 26 boys) were included in the study. The test group consisted of 33 study participants practicing cross-country skiing, while the control group consisted of 32 study participants who did not practice this sport. Gender was not a statistically significantly differentiating factor in the two groups $(\mathrm{p}=0.919)$.

Members of the control group attended the same schools as the participants qualified to the test group who attended classes with profiles other than sports. Biometric data of members from the test and control group are shown in Table 1. The data in both groups did not differ statistically significantly.

The study was conducted in the period preceding the commencement of preparation for the winter season in the Podlasie province at Primary School No. 32 in Bialystok, Public Junior High School No. 12 in Bialystok, Sports Schools Complex in Supraśl and primary school in Malawicze Dolne. The criterion for inclusion in the study group was the cross-country skiing training experience of over two years, and 11-16 age range, as well as written consents of participants and their parents or caretakers.

The criteria for exclusion from the test group were: a recent, severe injury that prevented a given athlete from attending training and conducting the test, practicing a sport other than cross-country skiing and lack of consent for participation in the study.

The study was divided into two stages. In the first stage, the participants were presented with a survey consisting of a personal questionnaire and 17 closedended and open-ended questions of single and multiple 
Tab. 1. Biometric data of the test and control group

\begin{tabular}{|c|c|c|c|c|c|c|c|}
\hline \multirow[b]{3}{*}{ Parameter } & \multicolumn{7}{|c|}{ Descriptive statistics } \\
\hline & \multicolumn{3}{|c|}{ Test group } & \multicolumn{3}{|c|}{ Control group } & \\
\hline & $\mathrm{x} \pm \mathrm{SD}$ & Min & $\operatorname{Max}$ & $\mathrm{x} \pm \mathrm{SD}$ & Min & $\operatorname{Max}$ & $\mathrm{p}$ \\
\hline Age [years] & $13.67 \pm 1.36$ & 11.00 & 16.00 & $13.63 \pm 1.31$ & 11.00 & 16.00 & 0.85 \\
\hline Body weight $[\mathrm{kg}]$ & $56.50 \pm 12.04$ & 37.00 & 85.00 & $57.00 \pm 5.69$ & 45.00 & 72.00 & 0.94 \\
\hline Height [cm] & $165.20 \pm 11.83$ & 145.00 & 188.00 & $165.30 \pm 4.28$ & 158.00 & 176.00 & 0.81 \\
\hline BMI $\left[\mathrm{kg} / \mathrm{m}^{2}\right]$ & $20.45 \pm 3.61$ & 14.18 & 32.34 & $20.85 \pm 1.68$ & 18.00 & 23.51 & 0.11 \\
\hline
\end{tabular}

choice. The survey contained data on training experience, the number of training sessions and starts in the season, a subjective assessment of skills, and information regarding the warm-up and other complementary sports activities. The next questions concerned injuries sustained during training or competition. These questions regarded the type of injury, the topography of injuries, symptoms, treatment provided and physiotherapy. A researcher was present in the room and explained the questions to the participants while they completed the survey.

Then in both groups, the FMS test was carried out with the use of a specialized assessment chart. The tests were conducted by a therapist who holds a valid FMS certificate.

The FMS test includes:

1. Deep Squat test. It is used to test the overall body mechanics and bilateral, symmetrical and functional mobility and stability of the hips, shoulders, knees, spine, and ankles.

2. Hurdle Step test. It is used to test the mobility and stability of the entire leg kinetic chain of and core, as well as stability of pelvis, torso and hip joints.

3. In-line Lunge. It is used to test the stability and mobility of the torso, as well as to determine the ability of the torso to counteract the rotary forces while maintaining the correct position.

4. Shoulder Mobility. Assessment of the bilateral mobility of the shoulder, combining the ability to internally rotate and adduction, as well as the ability of external rotation and abduction. This test is also used to determine the extent of mobility in the shoulder and thoracic spine.

5. Active Straight-leg Raise. It is used to assess the flexibility of the hamstring, as well as the gastrocsoleus muscles while maintaining the opposite leg (actively) extended.

6. Trunk Stability Push-up. It is used to test the stability of the torso in the sagittal profile during a symmetrical pushing movement of both arms.
7. Rotary Stability. Test of rotary stability in the sagittal profile during a symmetrical movement of both arms.

According to Lemiesz et al. methodology for performing the FMS test Includes the following criteria:

- The test is performed without a warm-up,

- The participant performs 3 repetitions of each task,

- The researcher assesses only the best trial,

- When in doubt, the researcher always gives a lower rating,

- The participant performs the test in a sports outfit and flat sports footwear [11].

The participants are rated on a scale of 0 to 3 points. To be awarded 3 points, the individual performing the test must carry out the task correctly without compensation patterns. If a given person received 2 points, he or she performed the test with compensation patterns. If a person cannot perform the test, 1 point is awarded. If pain occurs while the test is carried out, 0 points are awarded. A person can obtain 21 points maximum. If the examined person scores between 21 and 18 points, this means that he or she is healthy, his or her body maintains the correct movement pattern and the risk of overload or strain injury is minimal. However, a person who obtains from 17 to 15 points has distorted movement patterns and the occurrence of overload or strain injury is very probable. A score of 15 points or less means that there is a high risk of injury [12].

\section{Statistical analysis}

Statistical analysis of collected data was carried out in Statistica 13.1 developed by StatSoft. For the analysis of variables both parametric and nonparametric tests were used. The choice of the parametric test depended on the fulfillment of its basic assumptions, i.e., the conformity in the distribution of variables tested with the universally acknowledged distribution of variables (data), which was verified by applying the Shapiro-Wilk test. To assess the differences in the mean level of the statistical feature in two populations, the $\mathrm{t}$-Student test for independent variables was applied. In the alternative assessment, the non-parametric 
Mann-Whitney $U$ test was applied. The correlation between two variables that did not meet the criteria of universally acknowledged distribution of variables was determined by applying Spearman's rank correlation coefficient. The analysis of variables regarded as qualitative data was carried out by applying Pearson's chi-squared test. The strength of the relation between the variables in the $2 \times 2$ contingency tables (crosstabulation) was determined by applying the Phi (coefficient) test. Descriptive statistics were calculated for the numeric variables. The level of statistical significance was established at $\mathrm{p}<0.05$.

\section{Results}

For the members of the test group, the training experience was 4.67 years \pm 1.73 years on average. During the season, the study participants took part in competition $10.30 \pm 4.77$ times on average. They rated their skiing skills subjectively, at an average level of $6.97 \pm 1.99$ points. on a scale of $0-10$. During the week, the individuals taking part in the study trained $5.21 \pm 1.54$ times on average. Most members of the test group $(93.9 \%)$ performed warm-ups before proper training. 14 members of the test group (42.4\%) declared that they also do other sports activities complementary to their training. Within the control group, 15 people (46.9\%) engaged in physical activity in their free time (excluding skiing). The discrepancy between the groups regarding taking up additional physical activities was not statistically significant $(\mathrm{p}=0.718)$.

17 members of the test group (51.5\%) sustained injuries during training or competition. 15 members of the control group (46.9\%) suffered an injury while performing any type of physical activity other than cross-country skiing. This discrepancy was not statistically significant $(p=0.708)$. The frequency of occurrence of injuries also did not statistically significantly differentiate $(p=0.169)$, nor did the topography of injuries $(\mathrm{p}=0.745)$ (Fig. 1).

21 members of the test group (63.6\%) applied preventive training procedures to avoid injuries. Statistically, these athletes did indeed sustain injuries significantly less often than their competitors who did not incorporate preventive training $(\mathrm{p}=0.000)$.

The test and control groups did not differ significantly in the circumstances in which injuries occurred $(p=0.339)$. Only members of the test group required medical intervention as a result of sustained injury, which statistically significantly differentiated them from members of the control group $(p=0.044)$.

Only 3 members of the test group were provided with treatment (physiotherapy procedures). They were provided the treatment $2.33 \pm 1.15$ times a week on average for an average period of $3.67 \pm 2.08$ month(s), and they regained physical fitness after a month.

All athletes in the test group also practiced other sports, such as: sprinting, cycling, swimming, modern dance, long jump, hurdling, handball, football, long-distance running, and basketball. As a result of practicing these sports, the study participants suffered injuries such as micro-damages of the forearm, shoulder and knee joints, ankle and knee sprains, lower limb fractures, ankle, and radiocarpal joint sprains, bone fractures in the vicinity of the knee and radiocarpal joints, muscle strain, dislocation of lower limb fingers. The following training schemes were applied to prevent injuries: balance exercises, stretching, strength exercises, and stability training.

Sports most often practiced among members of the control group were: cycling, handball, running, karate,

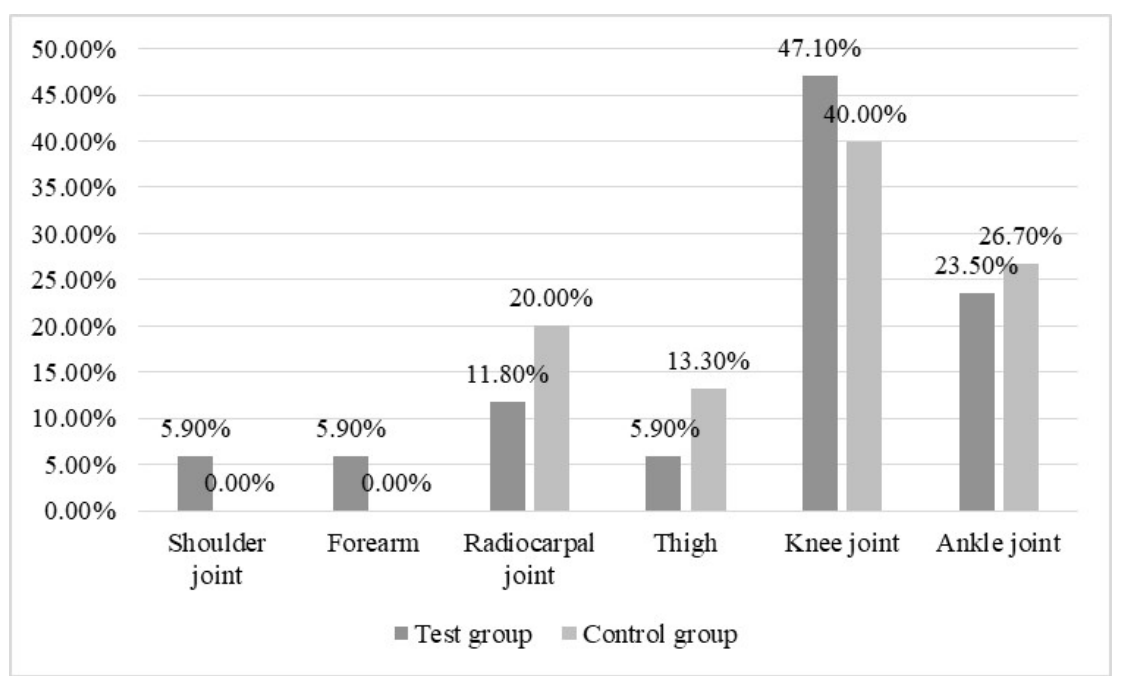

Fig. 1. Topography of injuries 
football, and volleyball. The most common injuries in this group were: ankle sprains and muscle strain.

Overall results of the FMS test regarding members of both the test group and the control group expressed on the FMS scale are presented in Table 2.

The interpretation of collected data regarding the risk of injury depending on the outcome of the FMS test and score obtained on the scale is illustrated in Figure 2. The assessment of the risk of injury in both examined groups did not differ statistically significantly $(\mathrm{p}=0.992)$.

Research showed a lack of a statistically significant relation between the FMS score and the training experience of the members of the test group $(p=0.739)$. Furthermore, no statistically significant relation was found between the FMS score and the number of injuries $(p=0.997)$. There were no significant differences in the FMS test results on account of sex of the study participants, as shown in Table 3.

Research also showed a lack of a statistically significant relationship between the number of sustained injuries and the training experience of the members of the test group ( $p=0.056)$, although this relationship was fairly close to the threshold of statistical significance. This correlation was positive $(\mathrm{R}=0.47)$, which could suggest an increase in the number of injuries along with acquiring more training experience by the study participants. Furthermore, no statistically significant relation was found between the FMS score and training experience of members of the test group $(\mathrm{p}=0.739)$, as well as between the FMS score and the number of injuries sustained by members of the test group ( $\mathrm{p}=0.997)$.

The test result in the test group depended on the age of its members It is a statistically significant factor. Chisquare is 28.282, $\mathrm{p}=0.013$. The ANOVA test results also show that a correlat ion exists between age groups $\mathrm{p}=0.002$.

\section{Discussion}

The aim of this study was to determine the functional state and to compare it with injuries occurring among young athletes practicing cross-country skiing.

Children's physiology significantly differs from one of the adults. Adamczyk et al. observed an upward trend in injuries as a result of sports activities. Most prone to injuries were athletes involved in sports, which required them to maximize their fitness. Often, this concerned people who practiced were sports on an amateur

Tab. 2. FMS test results in the test and control group

\begin{tabular}{lcccccccc}
\hline \multirow{2}{*}{ FMS - total score } & \multicolumn{1}{c}{ Descriptive statistics } \\
\cline { 2 - 9 } & $\mathrm{n}$ & $\bar{x}$ & $\mathrm{Me}$ & Min & Max & $\mathrm{Q} 1$ & $\mathrm{Q} 3$ & $\mathrm{SD}$ \\
\hline Test group & 33 & 16.67 & 18.00 & 1.00 & 21.00 & 16.00 & 19.00 & 3.64 \\
\hline Control group & 32 & 16.63 & 17.50 & 1.00 & 20.00 & 15.50 & 19.00 & 3.62 \\
\hline Total & 65 & 16.69 & 18.00 & 1.00 & 21.00 & 16.00 & 19.00 & 3.60 \\
\hline Significance $(\mathrm{p})$ & $\mathrm{Z}=0.20 \mathrm{p}=0.837$ & & & & & \\
\hline
\end{tabular}

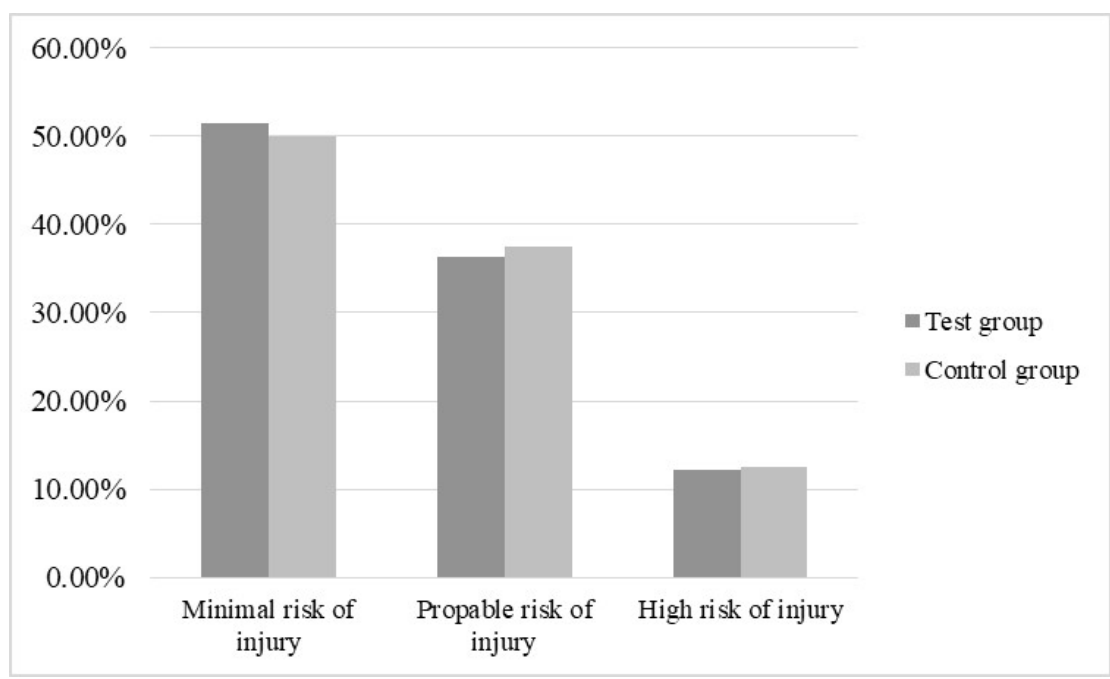

Fig. 2. Risk of injury as per the FMS test results 
Tab. 3. Description of the sum of FMS test results on account of sex of the study participants

\begin{tabular}{lcccccccc}
\hline \multirow{2}{*}{ FMS - total score } & \multicolumn{7}{c}{ Descriptive statistics } \\
\cline { 2 - 9 } & $\mathrm{n}$ & $\bar{x}$ & $\mathrm{Me}$ & Min & Max & Q1 & Q3 & SD \\
\hline Females & 20 & 16.65 & 18.00 & 1.00 & 21.00 & 15.50 & 19.00 & 4.44 \\
\hline Males & 13 & 16.92 & 17.00 & 14.00 & 20.00 & 16.00 & 18.00 & 2.02 \\
\hline Total & 33 & 16.76 & 18.00 & 1.00 & 21.00 & 16.00 & 19.00 & 3.64 \\
\hline
\end{tabular}

Significance $(p)$

$\mathrm{U}=0.68 \mathrm{p}=0.495$

level without in-depth knowledge of a given sport. [13]. Cross-country skiing is a sport that requires motor coordination skills necessary to master the alternating movements of the upper and lower extremities. This sport is characterized by various forms of training and special strength conditioning [14]. All these factors increase the risk of overloading the movement apparatus and, by consequence, injury. In a study by Boguszewski et al. [7], the authors proved that the most common injuries among skiers were: bruises, incised wounds, muscle strains, and sprains. Joints most prone to injury were: the knee joint, radiocarpal, ankle, and shoulderscapular joints, which coincides with the results of own research. Other authors have shown that the most frequently damaged parts of the body were: the knee joint, ankle joint and fingers of lower extremities [15]. Based on own research, it has been proven that the most common injuries include sprains, strains and bruising.

Authors of another study, after analyzing the results of 150 young athletes practicing cross-country skiing, proved that the body areas most exposed to injuries were the knee and ankle joints [16,]. Authors of yet another publication argued and proved that the most frequent injuries concerned the knee, shoulder-scapular joint, and lumbar section of the spine [17]. The results of the research presented in the aforementioned publication coincide with our findings.

Apart from the analysis of the specific nature of the sport that is cross-country skiing, another important element of the study described herein was the assessment of functional disorders of athletes. FMS is a screening tool that selectively assesses basic movement patterns to determine the risk of injury. In the study by Schneiders et al. [10] 209 physically active people aged 18 to 40 years were examined (108 women and $101 \mathrm{men}$ ), with no recent history ( $<6$ weeks) of musculoskeletal damages. As a result, the compliance factor (ICC3,1) was demonstrated, which proves the optimal compliance of the FMS test [18].

Performing the functional assessment by applying the FMS test is a popular method and data gathering tool used by physiotherapists. Currently, it is also used to test and assess professionals, such as firefighters and soldiers [19]. The credibility of the test is determined by the possibility of being repeated several times at different times by the same individual, or at the same time by two different people, and in both cases gives the same result. The FMS repeatability study showed that the test can be used to assess mobility in various sports. The compliance level in the Functional Movement Screen test results (FMS) carried out by two researchers was high (ICC $=0.98)$ [20].

Other significant advantages of the FMS test, which the authors point out, are safety, availability, and ease of execution, and the ability to assess the patient's functional state by observing movement patterns, as well as determine therapy progress and reduce the risk of injury [21].

Analysis of source texts shows that athletes who scored less than 14 points in the FMS test were more prone to injuries [22]. According to the interpretation of the FMS scale results, during the tests in the case of 33 athletes $(50.8 \%)$ the risk of injury was assessed as minimal, in the case of 24 athletes $(36.9 \%)$ it was defined as probable, and in the case of 8 athletes (12.3\%) as high. The assessment of the risk of injury in the two examined groups was similar, no statistically significant differences were found in this respect $(\mathrm{p}=0.992)$. It was also confirmed that applying the FMS test allows for monitoring and comparison of athletes' achievements. Athletes who had the lowest test score (below 14 points) later on sustained injuries. Researchers have shown that increased occurrence of injuries correlated with relatively low FMS test results [23].

One of the base assumptions of the FMS concept is that basic movement patterns are the outcome of the combination of other constituent elements, such as mobility, stability, and neuromuscular coordination. Their disorders contribute to the occurrence of abnormalities in the movement apparatus of a given person and predispose to compensation in various areas of the body, which increases the risk of injury for a given athlete [24]. 
Vrbanić et al. In a study on static and dynamic balance, proved that the stability indicators discussed in the article may be effectively used as factors in the detection of the risk of injury that arises as a result of abnormalities regarding neuromuscular control [19]. This means that movement deficits occur in the athletes' bodies, which are eventually replaced by incorrect compensation. In the study discussed herein, the researchers noted that both groups have problems in tests that require rotary stability.

The authors of this study found that just over half of the members of the test group (63.3\%) applied preventive training schemes and procedures to avoid injuries. It is safe to assume that this is associated with a low level of awareness regarding the risk of injury among athletes. Most often athletes used stretching, strength and stabilization training as preventative measures. Injuries occurred more often during training sessions. Every third skier had to resort to medical intervention in the past as a result of an injury. The study showed that whether an athlete sustained an injury indeed depended significantly on applying preventive training to prevent injuries. Athletes who carried out preventive training were less likely to get injured. The research by Boguszewski et al. [7] shows the significance of the trainer-physiotherapist relation. Research has confirmed faster recovery for athletes who have undergone immediate physiotherapy treatment. As part of the therapeutic procedure after an injury, the PRICEMM method was implemented [7].

In conclusion, one of the goals of own research was to demonstrate the practical value of the FMS test for the purposes of the prevention and correct diagnosis. Thorough knowledge of a given athlete's weaknesses will allow for better results next season. It was a good impulse for the coaches of the clubs from which the athletes were tested. They were instructed on the possibility of a functional assessment of their athletes. The study concerned the impact of injury assessment and its contribution to a more thorough recognition of functional hazards arising from cross-country skiing training, which could translate into developing optimal preparatory training.

It should be emphasized that this study allowed to determine the degree of injury occurring among young athletes practicing cross-country skiing (age range of 11-16 years). The quality and range of movement was examined, which in the future may contribute to the modification of the training scheme and implementation of exercises with which the athletes had the biggest problems. During the test, the participants were instructed on how to properly perform the exercises and were made aware of the consequences of neglecting preventive training.
Additionally, research in the current literature on the subject showed there were very few studies regarding the above-mentioned sport.

Despite the high compliance rate - ICC (3.1), own research was limited to only one test carried out by one researcher. An aspect that could also have an impact on the FMS test result is the time discrepancy, i.e. the time elapsed between the occurrence of injury or overload and the time the test was carried out. An additional problem encountered in the control group was the lack of knowledge of individual FMS tests among its members, which could be the reason for the incorrect performance of individual tasks that make up the entire test.

Another factor limiting research is the possibility of overinterpretation of the FMS test results in some sports. No information was found in the current literature regarding false interpretation of the FMS test results in case of cross-country skiers, although perhaps in case of joint hypermobility or an inexperienced researcher there may occur instances of overestimation of the FMS test results, which may lead to the imposition of too much training load and, as a result, injuries and contusions. Therefore, the authors of the study discussed herein recommend treating the FMS test as a screening tool indicating the risk of injury and introducing additional tests specific for a given sport to properly examine athletes practicing given type of sport.

Yet another limiting factor is the inability to exclude taking up other sports activities by members of the test group, either as part of the preparation for competition or simply for pleasure. The authors of this study excluded athletes who competed in other sport disciplines. Nowadays, the increasing availability and promotion of physical activity are an encouragement for people to try different sports. However, it cannot be ruled out that practicing different sport by members of the test group has in some way translated into overload, subsequently leading to injury.

\section{Conclusions}

1. Cross-country skiing training had no significant effect on musculoskeletal injuries.

2. The FMS test result did not correlate with previous injuries.

3. People who take up preventive training are less likely to sustain injuries.

\section{Funding}

This research received no external funding.

\section{Conflicts of interest}

The authors declare no conflict of interest. 


\section{References}

1. Świderska-Kopacz J, Marcinkowski JT, Jankowska K. Zachowania zdrowotne młodzieży gimnazjalnej i ich wybrane uwarunkowania. Cz. V. Aktywność fizyczna. Probl Hig Epidemiol. 2008, 89(2): 246-50.

2. Szczygielska-Babiuch A, Lipińska-Stańczak M, Skrzypek M, et al. Problem nadwagi, a sprawność fizyczna kobiet z osteoporozą - badania pilotażowe. Gerontol Pol. 2019; 27; 27-35.

3. Zagłoba-Kaszuba A, Huber J. Zarys rozwoju metod rehabilitacyjnych ze szczególnym uwzględnieniem technik prooprioceptywnego ułatwienia nerwowomięśniowego opartego na badaniach neurofizjologicznych. Now Lek. 2008; 77(5): 385-91.

4. Floreani M, Rejc E, Taboga P, et al. Effects of 14 days of bed rest and following physical training on metabolic cost, mechanical work, and efficiency during walking in older and young healthy males. PLoS One [Internet]. 2018 Mar [cited 201916 Nov]; 13(3): https://journals.plos.org/plosone/article?id=10.1371/ journal.pone.0194291.

5. Stöggl R, Müller E, Stöggl T. Do Maximal Roller Skiing Speed and Double Poling Performance Predict Youth Cross-Country Skiing Performance. J Sports Sci Med. 2017; 16(3): 383-90.

6. Bijnen F, Caspersen C, Feskens E, et al. Physical activity and 10-year mortality from cardiovascular diseases and all causes. The Zutphen elderly study. Arch Intern Med. 1998; 158: 1499-505.

7. Boguszewski D, Adamczyk JG, Niemczyk J. Charakterystyka uszkodzeń ciała występujących u młodych narciarzy biegowych. Pedagogics, Psychology, Medical-Biological Problems of Physical Training and Sports. 2011; 8: 109-14.

8. Sadowski G. Na nartach biegowych. Sklep Podróżnika, 3rd ed. Warszawa: Sklep Podróżnika; 2011.

9. Grygorowicz M, Głowacka A, Wiernicka M, Kamińska E. Kompleksowa ocena fizjoterapeutyczna podstawa profilaktyki pierwotnej urazów sportowych. Now Lek. 2010; 79(3): 240-44.

10. Schneiders A, Davidsson A, Horman E, Sullivan J. Funcional Movement Screen Normative Values in a Young Active Population. Int J Sports Phys Ther. 2011; 6(2): 75-82.

11. Lemiesz G, Iwańczyk K, Biernat R, et al. Zastosowanie testu funkcjonalnej oceny w praktyce. Prakt Fizjoter Rehabil. 2013; 39: 4-11.
12. Deydre S, Teyhen PT, Scott W, Chelsea L. The Functional Movement Screen: A Reliability Study. J Orth Sports Phys Ther. 2012; 42(6): 530-40.

13. Adamczyk J, Gurgun K, Pepłowski M. Charakterystyka rodzaju i częstotliwości występowania urazów w wyczynowym treningu w sportach siłowych. Roczniki Naukowe Wyższej Szkoły Wychowania Fizycznego i Turystyki w Białymstoku. 2012; Nr 8: 113-17.

14. Anioł-Strzyżewska K, Starosta W. Ocena specyficznej wydolności wysoko zaawansowanych zapaśników w wieloletnim cyklu treningowym. Rocz. Nauk. WSWiT Białystok. 2012; 8: 110-12.

15. Brzozowska E. Charakterystyka rodzaju i częstotliwości występowania urazów u zawodników trenujących biegi krótkie. Rozprawy Naukowe Akademii Wychowania Fizycznego we Wrocławiu. 2013; 43: 66-72.

16. Stöggl T, Welde B, Supej M, et al. Impact of Incline, Sex and Level of Performance on Kinematics during a Distance Race in Classical Cross-Country Skiing. JSSM. 2018; 17: 124-33.

17. Dziak A., Tayara S. Injuries in sport. Kraków: Kasper; 2000.

18. Szyguła Z, Trzaska T. Profilaktyka urazów sportowych u dzieci i młodzieży. Med Sport. 2007; 11(3): 29-33.

19. Vrbanić TS, Ravlić-Gulan J, Gulan G. Balance index score as a predictive factor for lower sports results or anterior cruciate ligament knee injuries in Croatian female athletes--preliminary study. Collegium Antropologicum. 2007; 31(1): 253-8.

20. Kałużna A, Kałużny K, Wołowiec $€$, et al. Analysis of the Conformity Level of an Assessment in the Functional Movement Screen Test. JSHS. 2017; 7(8): 162-69.

21. Minick K, Kiesel B, Burton L, Taylor A, Plisky P, Butler R. Interrater Reliability of the Functional Movement Screen. J Strength Cond Res. 2010; 24(2): 479-86.

22. Teyhen DS., Shaffer SW, Lorenson CL, et al. The Functional Movement Screen: A Reliability Study. J Orthop Sports Phys Ther. 2012; 42(6): 530-40.

23. Kiesel K, Plisky F. Can Serious Injury in Professional Football be Predicted by a Preseason Functional Movement Screen. N Am J Sports Phys Ther. 2007; 2(3): 147-58.

24. Shultz R, Anderson SC, Matheson GO. Test-retest and interrater reliability of the functional movement Screen. J Athl Train. 2013; 48(3): 331-6. 